\title{
ISOLATION OF EKATETRONE, A NEW METABOLITE OF PRODUCING VARIANTS OF STREPTOMYCES AUREOFACIENS
}

\author{
M. Podojil, Z. VaněK, V. Přikrylová and M. Blumauerová \\ Institute of Microbiology, Czechoslovak Academy of Sciences, \\ 14220 Praha 4-Krč, Czechoslovakia
}

(Received for publication April 13, 1978)

\begin{abstract}
From a mixture of substances formed by producing strains of Streptomyces aureofaciens under conditions of submerged fermentation a new metabolite, ekatetrone, was isolated. Its isolation and basic physical and chemical data are described. Ekatetrone is a quinone derivative with a carboxamide group. In tests in vitro with cells of EHRLICH's ascites tumour evidence was provided that ekatetrone inhibits proteo- and nucleosynthesis.
\end{abstract}

Investigations of metabolites of Streptomyces aureofaciens strains were conducted in particular by McCormick et al. ${ }^{1)}$ For the biosynthesis of tetracyclines there is experimental evidence for the stages following the production of 6-methylpretetramide ${ }^{2}$, i.e. after closure of the linear hypothetical nonaketide. None of the assumed metabolites of the preceding stages of the biosynthetic pathway has been hitherto isolated. Simpler substances, such as trans-2,3-dihydro-3-hydroxyanthranilic acid isolated from a strain of Streptomyces aureofaciens ${ }^{3)}$, or aromatic derivatives from a mutant strain of Streptomyces rimosus ${ }^{4}$, obviously are in no direct relationship with the biosynthesis of tetracyclines. Among substances simpler than pretetramides, which are themselves proven members of the biosynthetic pathway of tetracyclines, so far two have been described, protetrone ${ }^{5)}$ and its methylanthrone analogue ${ }^{6}$. These two substances are, however, not on the main metabolic pathway. They are shunt metabolites with an open ring $A$ of the molecule of pretetramide. It is also possible that the hypothetical nonaketide is closed to form an anthracene derivative and only in a subsequent step aromatization takes place and pretetramide is formed ${ }^{7}$.

The submitted paper describes another natural metabolite with a quinone skeleton, isolated from Streptomyces aureofaciens, called ekatetrone ${ }^{8)}$. Conditions for its formation, isolation, and its basic physical and chemical constants and biological action are described.

\section{Cultivation}

Sporulation and cultivation media were prepared according to Herold et al. ${ }^{9)}$ with addition of an aqueous solution of benzylthiocyanate to stimulate the formation of metabolites. ${ }^{10}$ ) Condition of laboratory fermentation on a reciprocal shaker (frequency $1.4 \mathrm{~Hz}$ ) in 500 -ml flasks were adopted from the work of Blumaueroví et al. ${ }^{11}$ ) Cultivation in stainless fermenters with a volume of 1,000 liters filled with 600 -liter medium, was biphasic: after 24 hours cultivation the vegetative inoculum prepared on a reciprocal shaker (frequency $1.4 \mathrm{~Hz}$ ) was transferred to a seed-tank (volume 50 liters, filling 30 liters); the production tank was inoculated with the 20 -hour inoculum from the seed-fermenter. Cultivation conditions: temperature $28^{\circ} \mathrm{C}$, frequency of mixing $3 \mathrm{~Hz}$, aeration 0.5 volume/liter volume of medium/min. The fermentation was completed in 96 hours.

Ekatetrone production was investigated during the 24th, 72 nd and 96 th hour of fermentation by 
circular paper chromatography on Whatman paper No. 1 and by thin-layer chromatography on silica gel (Kieselgel G, Merck) and on a polyamide (Woelm).

Because of the varied mixture of metabolites in the extract from the mycelium it was essential to work with the fraction containing ekatetrone after purification by column chromatography on polyamide.

The production of tetracycline antibiotics was assessed spectrophotometrically after transformation to anhydrotetracyclines ${ }^{12)}$.

Of the seven investigated strains the followings were from the collection of the Research Institute of Antibiotics and Biotransformations in Roztoky: Streptomyces aureofaciens 1717, 111158 and 84/54 (producing strains) and Bg (low producing strain). The low producing strain NMG-2 and strain B-96 and UV-115 (non-producing) were mutants described by BLUMAUEROVÁ et al. ${ }^{11)}$

\section{Isolation and Characterization}

On completion of fermentation of strains of Streptomyces aureofaciens the cultivation medium was acidified and the mycelium was separated. Ekatetrone was obtained by extraction of the mycelium with a polar organic solvent, and chromatographic separation of the mixture of metabolites, precipitated from the extract with petroleum ether. The last purifying operation is recrystallization. We quote two examples of ekatetrone isolation from laboratory fermentation and fermenter.

The mycelium (1 kg wet weight) after filtration of the culture of the strain Streptomyces aureofaciens $84 / 54$ from the reciprocal shaker (200 flasks; 11.5 liters), acidified to $\mathrm{pH} 2.5$ with oxalic acid, was extracted with methanol $(2 \times 1.5$ liters $)$ at $40^{\circ} \mathrm{C}$. The methanolic extracts were combined and evaporated in vacuum at a temperature of $40^{\circ} \mathrm{C}$ to a volume of $c a .200 \mathrm{ml}$. From the concentrate the mixture of metabolites was precipitated by addition of petroleum ether $(400 \mathrm{ml})$. The separated precipitate $(3.8 \mathrm{~g})$ was triturated with methylisobutyl ketone $(150 \mathrm{ml})$; the undissolved residue was filtered off and the filtrate was applied to a polyamide column $(3 \times 34 \mathrm{~cm} ; 100 \mathrm{~g}$; Chemical Works Ružomberok). The column was developed with methylisobutyl ketone and fractions of $20 \mathrm{ml}$ were collected. Fractions $59 \sim 61$ after about 5 hours standing at laboratory temperature crystallized and by recrystallization from acetic acid we obtained a chromatographically uniform preparation of ekatetrone $(4.9 \mathrm{mg})$.

The fermentation medium (600 liters) after cultivation of strain Streptomyces aureofaciens 1717 in the fermenter was acidified with hydrochloric acid to $\mathrm{pH} 2.0$. The mycelium was separated and washed with distilled water. The mycelium $(50 \mathrm{~kg}$ wet weight) was extracted with ethyl acetate $(3 \times$ 33 liters) for one hour at laboratory temperature under constant stirring. The ethyl acetate extracts after filtering were combined and evaporated at $35^{\circ} \mathrm{C}$ in a vacuum evaporator to a volume of 4.1 liters. By addition of petroleum ether ( 5 liters) to this concentrate the mixture of metabolites was precipitated $(60 \mathrm{~g})$, and after filtration it was dissolved in methanol (1.2 liters). Ekatetrone was isolated from the mixture by column chromatography on polyamide $(0.5 \mathrm{~kg} ; 8 \times 25 \mathrm{~cm})$. To the column $150 \mathrm{ml}$ of the methanolic solution ( $7.5 \mathrm{~g}$ of the mixture of substances) were applied. The column was developed with methanol and fractions of $50 \mathrm{ml}$ were collected. From the combined yellow fractions 3 and 4 after brief standing at laboratory temperature ekatetrone crystallized as yellow needles $(15.4 \mathrm{mg})$.

The methanolic solution of the metabolite mixture was processed by this procedure on 8 columns and a total of $120 \mathrm{mg}$ ekatetrone were obtained. Recrystallization from acetic acid yielded $78.2 \mathrm{mg}$ of ekatetrone. The elution of ekatetrone from the column is selective. The other substances remain ir- 
reversibly bound to the polyamide column. The yields of ekatetrone indicate that it is a minor metabolite.

\section{Characteristics of Ekatetrone}

Ekatetrone forms yellow crystals, melting point $270 \sim 272^{\circ} \mathrm{C}$ (decomposition), $[\alpha]_{D}^{25}+304$ (c 0.169 , dimethylformamide). High resolution mass spectrometry (Varian MAT 311) gives $\mathbf{M}^{+} 367.0692$ corresponding to an empirical formula of $\mathrm{C}_{19} \mathrm{H}_{13} \mathrm{NO}_{7}$ (367.0691). Elemental analysis gives $\mathrm{C}, 62.50$; $\mathrm{H}, 3.77$; N, $4.11 \%$. Calculated C, 62.12; H, 3.57; N, 3.81\%.

Ekatetrone has a low solubility in methanol, ethanol, dioxane, ethyl acetate, and acetone. It is practically insoluble in benzene and petroleum ether. It is readily soluble in acetic acid, formamide, dimethylformamide, dimethyl sulphoxide. In concentrated sulphuric acid it dissolves to a brownish red, in $2 \mathrm{~N}$ aqueous sodium hydroxide to a magenta red solution. An alkaline solution of ekatetrone is decolorized reversibly with sodium dithionite. With $5 \%$ methanolic ferric chloride a brown colouration is obtained. After slight heating ekatetrone gives a positive GIBBs test ${ }^{13)}$. HofmanN degradation of ekatetrone suggests the presence of a carboxamide group. Distillation of ekatetrone with zinc dust gives as the main product an anthracene $\lambda_{\max }$ (cyclohexane) 221 (4.29), 246 (4.99), 253 (5.33), 291 (2.94), 309 (3.13), 323 (3.48), sh 335, 339 (3.76), sh 352, 357 (3.94), sh 371, 376 (3.92); nm (log $\epsilon$ ) (compare with FrIEDEL and ORCHIN ${ }^{14)}$, spectra No. 388, 389, 390, 391). Its spectrum differs from those of naphtalene, naphthacene and phenanthrene (FrIEDEL and ORCHIN ${ }^{14)}$, spectra No. 195, 532 and 341).

The chromatographic behaviour of ekatetrone is described in Table 1.

Table 1. Rf values of ekatetrone.

\begin{tabular}{l|c|c}
\hline Type of chromatography & System $^{\mathrm{a}}$ & $\mathrm{Rf}^{\mathrm{b}}$ \\
\hline PC (Whatman no. 1) & $\mathrm{S}_{1}$ & 0.80 \\
TLC (Kieselgel G, Merck) & $\mathrm{S}_{2}$ & 0.40 \\
TLC (Kieselgel G, Merck) & $\mathrm{S}_{1}$ & 0.40 \\
TLC (polyamide Woelm) & $\mathrm{S}_{1}$ & 0.55 \\
\hline
\end{tabular}

a System $\mathrm{S}_{1}$ : chloroform-1-butanol-MCILvain's buffer $\mathrm{pH} 4.5,4: 1: 5^{15)}$.

System $\mathrm{S}_{2}$ : chloroform-formamide-acetic acid, $15: 15: 1$.

b detection in ultraviolet light $(254 \mathrm{~nm})$ as a red fluorescent spot.

The ultraviolet and visible spectra of ekatetrone (Fig. 1) show absorption maxima $\lambda_{\max }$ (methanol) 227 (4.53), 252 (4.30), 276 (4.38), 375 (3.77), 411 (3.64); $\mathrm{nm}(\log \epsilon)$. After alkalization
Fig. 1. Ultraviolet and visible spectra of ekatetrone in methanol.

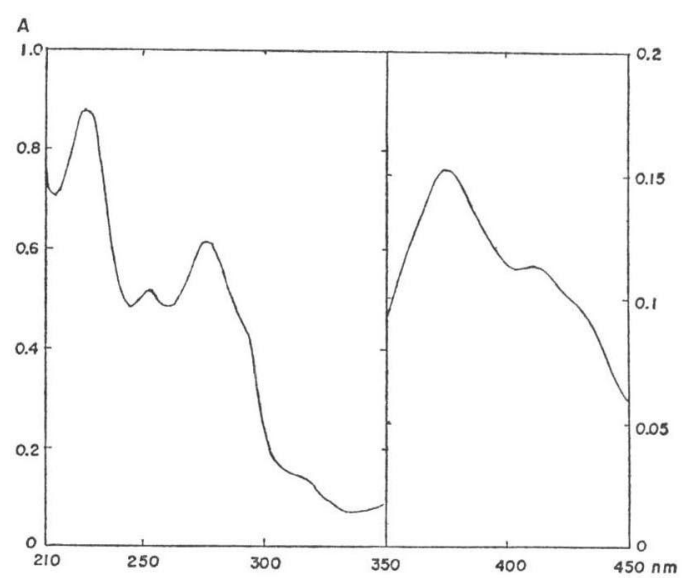

of ekatetrone a bathochromic shift from the value of $\lambda_{\max } 411 \mathrm{~nm}$ in the visible spectrum to $480 \mathrm{~nm}$ ( $\log \epsilon 3.52$ ) occurs. The infrared spectrum (Fig. 2) displays absorption in the area of valency vibrations $\mathrm{NH}\left(3490,3360 \mathrm{~cm}^{-1}\right)$ and CO groups $\left(1705,1675,1660,1640 \mathrm{~cm}^{-1}\right)$.

The interpretation of all the above characteristics suggests that ekatetrone is a quinone substance with a carboxamide group. It differs from protetrone and its methyl anthrone analogue ${ }^{5,6)}$. The structure determination of ekatetrone is described in a subsequent paper ${ }^{16)}$. 
Fig. 2. Infrared spectrum of ekatetrone ( $\mathrm{KBr}$ tablet).

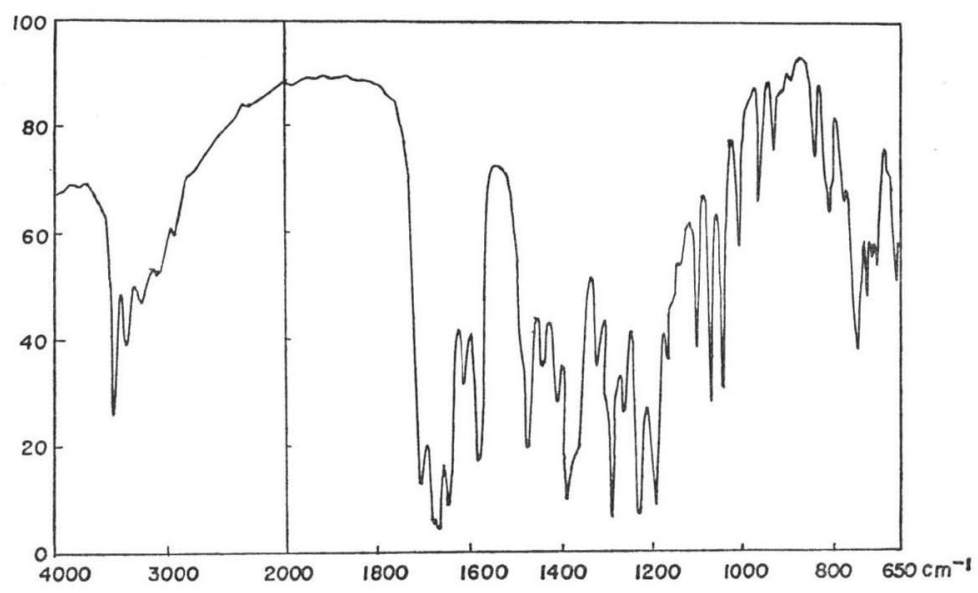

\section{Biological Activity}

Ekatetrone does not exert an antibiotic effect on bacteria and yeasts. This was tested by the plate method with the following test microorganisms: Bacillus subtilis, Escherichia coli and Candida albicans. Ekatetrone was dissolved in dimethyl sulphoxide to a concentration of $500 \mu \mathrm{g} / \mathrm{ml}$ and diluted with methanol to concentration of 50.0, 25.0, 12.5, 6.2, 3.1 and $1.5 \mu \mathrm{g} / \mathrm{ml}$.

In experiments in vitro ekatetrone inhibits nucleo- and proteosynthesis of cells of EHRLICH's ascitic carcinoma (EAC) $)^{17)}$. The inhibiting action was assayed as the reduced incorporation of the appropriate precursor into EAC cells, as compared with controls. From Table 2, it is apparent that ekatetrone had a marked effect in particular on the inhibition of L-valine incorporation. For concentrations of ekatetrone down to $10 \mu \mathrm{g} / \mathrm{ml}$ the inhibition of L-valine incorporation does not decline markedly. Only at a concentration of $5 \mu \mathrm{g} / \mathrm{ml}$ and less do we observe a steep decline of inhibition of L-valine incorporation.

Table 2. Inhibition of $\mathrm{L}$-valine ${ }^{14} \mathrm{C}(\mathrm{U})$ incorporation into $\mathrm{EAC}$ cells in relation to ekatetrone concentration.

\begin{tabular}{c|c|c|c|c|c|c|c|c|c}
\hline $\begin{array}{c}\text { Ekatetrone concentration } \\
(\mu \mathrm{g} / \mathrm{ml})\end{array}$ & 50.0 & 25.0 & 12.5 & 10.0 & 5.0 & 2.0 & 1.0 & 0.5 & 0.1 \\
\hline $\begin{array}{c}\text { Inhibition of incorporation } \\
(\%)\end{array}$ & 78.6 & 77.4 & 75.6 & 77.2 & 43.7 & 27.9 & 17.0 & 14.9 & 9.9 \\
\hline
\end{tabular}

\section{Discussion}

The presence of ekatetrone as an accompanying minor substance was proved only in producing strains of Streptomyces aureofaciens under conditions optimal for tetracycline formation $(2,500$ $4,100 \mu \mathrm{g} / \mathrm{ml}$ at the 96th hour of fermentation). In low-producing strains (maximum tetracycline production $300 \mu \mathrm{g} / \mathrm{ml}$ ) and non-producing strains ekatetrone was not detected. Typically, ekatetrone was found only in the final stages of fermentation. From these experimental data we may suggest a possible biogenetic position of ekatetrone. If the rate of synthesis of the basic building units (malonyl CoA) is higher than the rate of the synthesis of intermediary products in the main metabolic pathway leading to tetracyclines, the excess of precursors is diverted to metabolic side-pathways ${ }^{7)}$. This may be the 
situation in our producing strains of Streptomyces aureofaciens and the excessive precursors are used for the formation of ekatetrone.

Direct experimental evidence of the biogenetic position of ekatetrone is difficult to obtain. So far it did not prove possible to isolate a blocked mutant producing ekatetrone. For this reason cosynthetic experiments which could locate the position of ekatetrone in the biosynthetic pathway of tetracyclines have not yet been implemented. Preliminary experiments with tritium-labelled ekatetrone did not prove the incorporation of the label into the tetracycline molecule.

\section{Acknowledgements}

The authors wish to express their appreciation to The Institute of Antibiotics and Biotransformations, Roztoky, for pilot plant fermentation. The help of Dr. FuskA from The Slovak Technical University Bratislava with EAC tests in vitro is highly appreciated.

\section{References}

1) McCormick, J. R. D.: Biogenesis of antibiotic substances. p. 73, Publishing House of the Czechoslovak Academy of Sciences, Prague, 1965

2) МсCовміск, J. R. D.: Genetics and breeding of Streptomyces. p. 163, Yugoslav Academy of Sciences and Arts. Zagreb, 1969

3) McCormick, J. R. D.; J. Reichenthal, U. Hirsch \& N. O. Sjolander: Biosynthesis of the tetracyclines. III. A new amino acid from Streptomyces aureofaciens: (+)-trans-2,3-Dihydro-3-hydroxyanthranilic acid. J. Am. Chem. Soc. 84: 3711 3714, 1962

4) Catlin, E. R.; C. H. Hassall \& B. C. Pratt: Biosynthesis of phenols. XIV. Isolation of some shikimic acid-derived metabolites from mutant strains of Streptomyces rimosus unable to produce oxytetracycline. Biochim. Biophys. Acta 156: 109 118, 1968

5) McCormick, J. R. D. \& E. R. Jensen: Biosynthesis of tetracyclines. X. Protetrone. J. Am. Chem. Soc. 90: $7126 \sim 7127,1968$

6) McCormick, J. R. D.; E. R. Jensen, N. H. Arnold, H. S. Corey, U. H. Joachim, S. Johnson, P. A. Miller \& N. O. SJolander: Biosynthesis of tetracyclines. XI. The methylanthrone analog of protetrone. J. Am. Chem. Soc. 90: 7127 7129, 1968

7) VANĚK, Z.; J. Cudlín, M. BlumauerovÁ \& Z. HostÁleK: How many genes are required for the synthesis of chlortetracycline. Fol. Microbiol. 16: $225 \sim 240,1971$

8) Podojil, M.; Z. Vaněk, J. Vokoun, J. Suchý, M. Vondráček, J. VondráčKová \& A. Benda: The way of ekatetrone isolation. Czechoslovak Patent, 140917, Apr. 15, 1971

9) Herold, M.; E. BĚLíK \& J. DoskočIL: Biosynthesis of chlortetracycline without maintenance of aseptic conditions. Giorn. Microbiol. 2: 302 311, 1956

10) Pecák, V.; S. Č́̇̌źek, J. Musil, L. Čerrkes, M. Herold, E. Bělík \& J. Hoffman: Stimulation of chlortetracycline production by benzyl thiocyanate. J. Hyg. Epidemiol. Microbiol. Immunol. (Prague) 2: $111 \sim 115,1958$

11) Blumauerová, M.; M. Mraček, J. VondráČKová, M. Podojil, Z. HošŤálek \& Z. VaněK: Regulation of biosynthesis of secondary metabolites. IX. The biosynthetic activity of blocked mutants of Streptomyces aureofaciens. Fol. Microbiol. 14: 215 225, 1969

12) Levine, J.; E. A. Garlock \& H. Fischbach: The chemical assay of aureomycin. J. Amer. Pharm. Assoc. (Sci. Ed.) 38: 473 476, 1949

13) KING, F. E.; T. J. KING \& L. C. Manning: Gibbs reaction and constitution of jacareubin. J. Chem. Soc. 1957: $563 \sim 566,1957$

14) Friedel, R. A. \& M. Orchin: Ultraviolet spectra of aromatic compounds. John Wiley \& Sons., Inc., Pennsylvania, 1951

15) UrX, M.; J. VondráčKová, L. Kovařík, O. HorskÝ \& M. Herold: Papierchromatographie der Tetracyclinstoffe. J. Chromatogr. 11: 62 65, 1963

16) Přikrylová, V.; M. Podojll, P. Sedmera, J. Vokoun, Z. VaněK \& C. H. Hassall: The structure of ekatetrone, a metabolite of strains Streptomyces aureofaciens. J. Antibiotics 31: 855 862, 1978

17) Fuska, J.; M. PodoJIL, A. FuskovÁ \& Z. VANĚK: Inhibition of proteo- and nucleic acids synthesis in EHRLICH ascites carcinoma cells by some new metabolites isolated from mutants Streptomyces aureofaciens. p. 24, Proc. EACR Symposium on Mechanisms of action of cytostatic agents, Budapest, 1972 